\title{
Application potential analysis of heat accumulator for mining mechanisms
}

\author{
Radim Rybár ${ }^{1 *}$, and Martin Beer ${ }^{1}$ \\ ${ }^{1}$ Technical University of Košice, Faculty of Mining, Ecology, Process Control and Geotechnologies, \\ Institute of Earth Resources, Letná 9, Košice, Slovakia
}

\begin{abstract}
The paper deals with the application potential analysis of heat accumulators for mining machines working in cold climatic conditions. The proposed concept works with the idea of accumulating waste heat generated by the operation of an internal combustion engine, with use of exhaust heat, heat from the radiator and heat from the drive of the hydraulic system. An important innovative element is the use of the heterogeneous structure of phase change material - sodium acetate as a storage substance and a metal foam matrix. The use of sodium acetate enable to store heat for a long period of time without heat loss and the metal foam matrix significantly increases the thermal conductivity. The presented paper deals with the analysis of the functionality of the heat accumulator prototype and with the description of the key phase of the working cycle - heat accumulation.
\end{abstract}

\section{Introduction}

World energy consumption, demand for raw materials and negative environmental impacts have seen a significant increase in tens of percent over recent decades [1]. Thanks to this fact, it is necessary to carry out geological exploration work and, then, mining itself in an increasingly wide scale and in places that pose a challenge not only for the operators but also for the machinery itself. Such places undoubtedly include Arctic regions with cold climatic conditions. The operation of machines in such conditions represents a significant increase in costs, due to increased fuel consumption or the need to preheat the machine part after prolonged downtimes. One possibility is the utilization of waste heat and its subsequent accumulation.

Useful heat resulting from the operation of mining machinery with combustion engine (stationary or mobile) is unused energy potential in the form of exhaust gas, coolants or air, which are heat sources with varying energy levels. This potential can be suitably converted to further uses and bring immediate savings in fuel consumption by improving the operating parameters of the machines, respectively extending the lifecycle in terms of reducing wear of individual parts, and thus extended service intervals [2,3]. Since mining industry is energy intensive sector, a lot of approaches that can reduced energy demands are studied including use of renewable energy sources or energy storage [5-7]. A small range of

\footnotetext{
* Corresponding author: radim.rybar@tuke.sk
} 
industrial applications and technology is dealing with useful heat, i.e. heat recuperation with direct use, thermoelectric generators [8] or heat storages with delayed use [9].

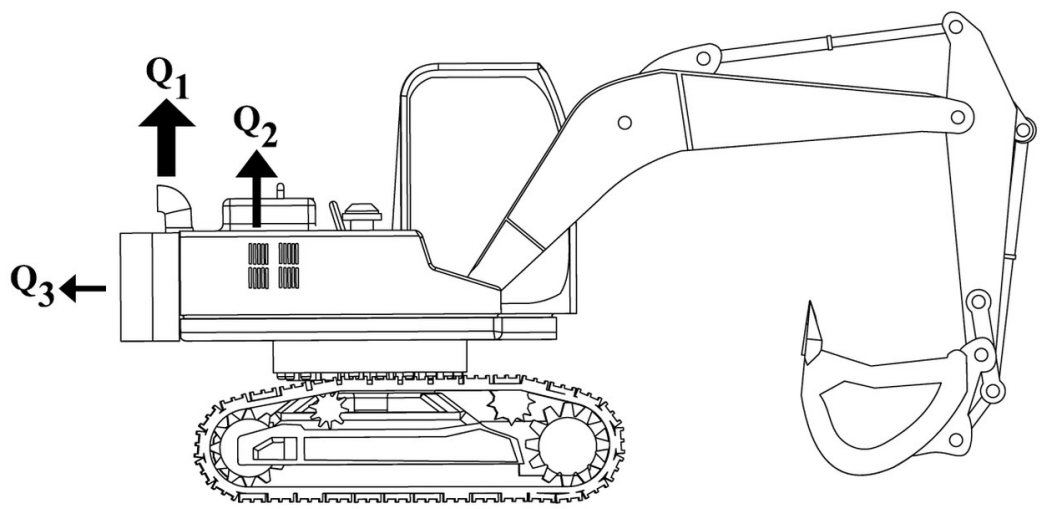

Fig. 1. Example of the most important sources of useful heat from excavator, as typical mining machines, $\mathrm{Q}_{1}$ - heat from exhaust gas, $\mathrm{Q}_{2}$ - coolants, $\mathrm{Q}_{3}$ - hydraulic circuit.

Identifying sources of useful heat of mining machines is mainly focused into the engine compartment, where are located heat exchangers of operation fluid and gases, outlet of exhaust gas and drivetrain of hydraulic circuit (see Fig. 1). In terms of energy flow is dominant exhaust gas outlet from combustion engine that provides constant heat flux with sufficient thermal capacity. To a lesser degree is possible to use heat fluxes from the cooling space of operation fluids and gases, respectively from a hydraulic pump in hydraulic circuit (see Fig. 2). The last mentioned sources represent sources with low energy potential which should be advantageous for designs with different concepts of heat accumulators. The heat energy contained in the exhaust gas and cooling systems generally represents $60-70 \%$ of the total energy content of the fuel [10].

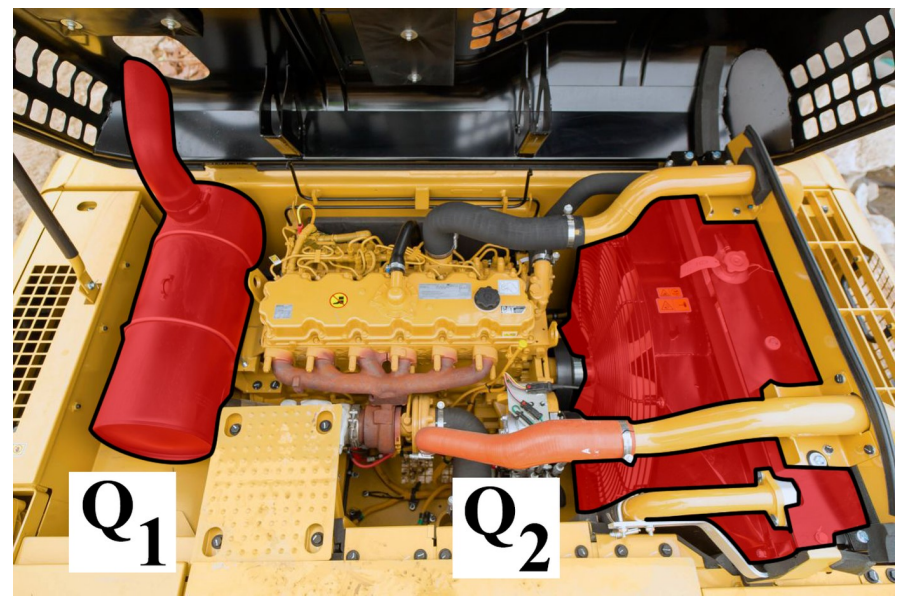

Fig. 2. Graphical illustration of waste heat source in engine area.

Heat accumulation and storage unit with appropriate design and thermal capacity located in the corresponding position of the mining machine can improve economy of operation and the life of the construction parts particularly in difficult climatic conditions. A good example is the possibility of elimination of cold engine starts where the heatstorage unit allows heating of the engine prior to the start of operation with heat stored from 
the previous operation. The inclusion of the heat-storage unit allows obtaining a balanced operation of engine (or machine) in terms of reduction of thermal shocks and stress of working fluids, which represents negative side of operation. However, such constructed heat-storage unit is bounded to assumption that it will be able to overcome longer periods with stored heat without progressive reduction of the amount of accumulated heat. This allows some materials using phase change, which also may be in the state of supercooling. Concept of heat-storage unit proposed by authors that works with phase change materials (hereinafter PCM) in combination with metal foams is a suitable technical solution that can be applied at the above mentioned operating conditions of machines, which are not limited to the mining machines, but span a wide range of machinery producing significant amounts of energy in the form of useful heat. The incorporation of the proposed heat-storage units into the mining machines is also suitable due to their significant operation weight and thus ratio of weight of heat-storage unit to total weight of machine is a negligible.

From physical point of view is accumulation of heat possible in several ways: accumulation of sensible heat, latent heat, sorption heat and chemical heat [11]. In recent years is getting into attention use of heat accumulation operating on the principle of phase change of PCM where latent heat is stored. As reported in [12] latent heat is one of the most effective ways to store thermal energy. Materials suitable for heat storage should achieve the greatest values of accumulation of heat energy in a minimum volume of material. Additional requirements for PCM include: cyclic stability, flame resistance, low volume changes associated with phase changes, non-corrosive properties and low tendency to supercooling.

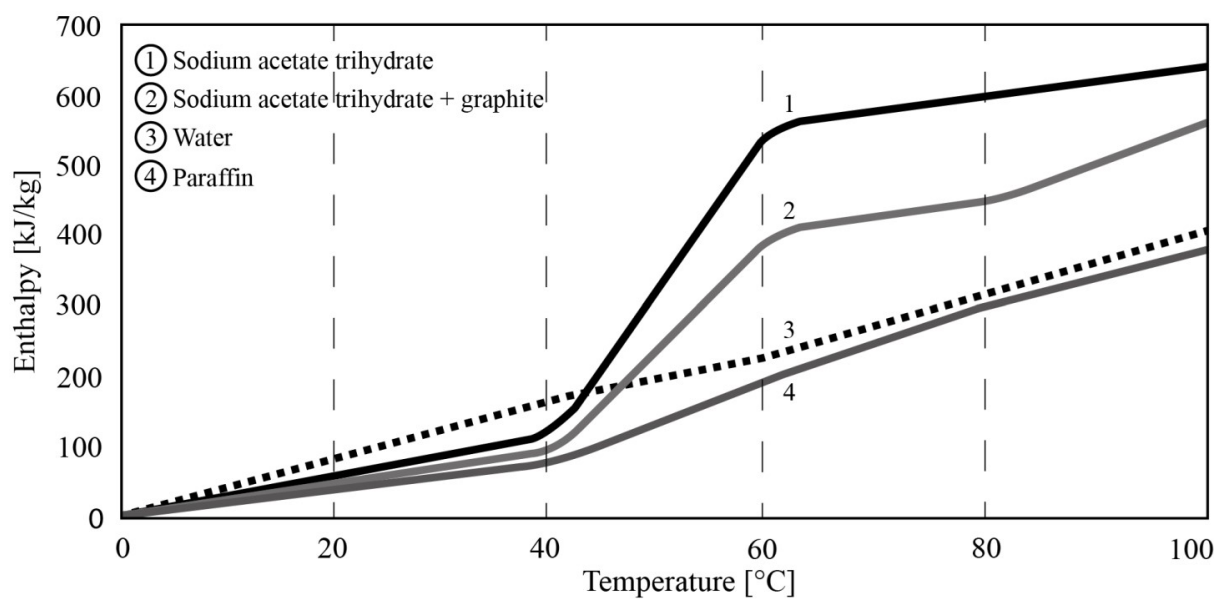

Fig. 3. Comparison of heat-storage capacity of selected materials [13].

In terms of the ratio between the storage capacity of the materials and their weights are organic (waxes) and inorganic (hydrated salts) PCM almost comparable. In comparison of the amount of accumulated heat to the volume of accumulation material there is a clear significant difference in density between the accumulation of organic (waxes) and inorganic (hydrated salt) PCM.

The operating cycle of such conceived heat-storage units can be divided into three phases, the first phase involves the accumulation (charging) of the heat-storage unit, in the second phase there is a stabilization of heat-storage unit and in the third phase is the release of stored energy. The temperature of accumulation material (PCM) is increasing in the charging phase. In first part of this phase is accumulated sensible heat without phase change of PCM, for sodium acetate trihydrate is this part limited with temperature of $58^{\circ} \mathrm{C}$. Above this temperature is accumulated latent heat, this accumulation is ended at the moment when 
phase change from solid to liquid phase is completed in whole volume of heat-storage unit, i.e. when PCM receive all latent heat in relation to its volume (e.g. for the sodium acetate trihydrate it is $265 \mathrm{~kJ} . \mathrm{kg}-1$ ). If the heat-storage unit received more energy the temperature of PCM is increasing and only sensible heat is accumulated. First phase is followed by supercooling phase, which stabilizing heat-storage unit by preventing unwanted nucleation and thus premature release of the stored energy [13]. When PCM is in supercooling phase, heat-storage unit is in state of liquid phase below to point of phase change $\left(58^{\circ} \mathrm{C}\right.$ for sodium acetate trihydrate). The course of the temperature for the phases of accumulation and the supercooling are shown in Fig. 3.

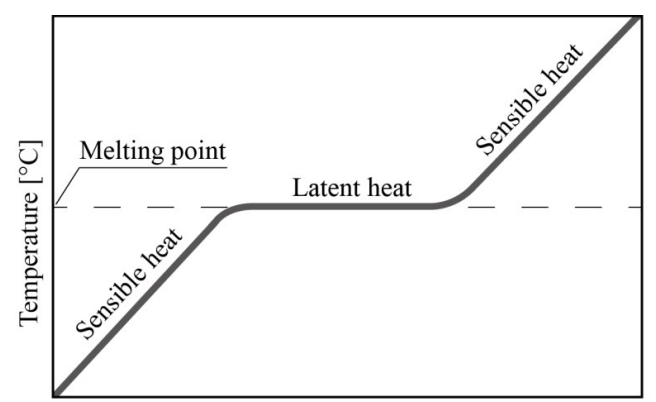

Energy [J]

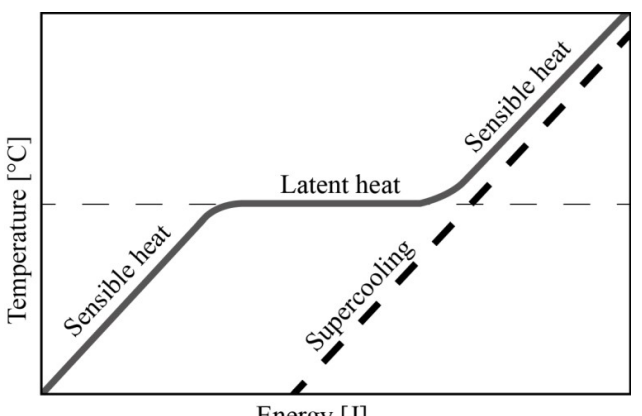

Energy [J]

Fig. 4. Temperature curves of PCM for accumulation phase (left) and supercooling phase (right) [13].

An important characteristic of PCM materials in terms of thermal properties is their low thermal conductivity [14]. This feature presents some conceptual limitation of creating heat-storage unit based on PCM, which is reflected in the length of time for melting and solidifying of PCM. Problems related to the heat distribution in PCM are presented, for example in [15] wherein author experimentally tested possibility of improving heat transfer in PCM (paraffin wax) with use of the open cell structure of the copper foams. By adding metal foams in paraffin, thermal conductivity of the created structure increased from 16 to 18 times compare to pure paraffin. Another way of increasing the thermal conductivity of PCM is application of additive, which produces heterogeneous mixture with PCM [16-18].

A specific concept of the storage unit, which is presented in this paper, is a combination of PCM material - sodium acetate trihydrate and spatial structure consisting of blocks of metal foam with an open pore structure that in this heterogeneous spatial arrangement creates heat exchanger. This unique combination is designed with intent to eliminate characteristically low thermal conductivity of PCM materials.

\section{Methodology}

The manufactured and assembled prototype of heat-storage unit has a cylindrical shape with base in form of annulus. Used metal foam has an outer diameter of cylinder of $50 \mathrm{~mm}$ and inner of $12 \mathrm{~mm}$. Height of the metal foam cylinder, and thus the whole heat-storage unit, is $103 \mathrm{~mm}$. The metal foam is characterized by an open structure of pores with pore density of 10 PPI (pores per inch) and total porosity of $96 \%$, the basic material of metal foam is copper. The second component of the heat-storage unit, thus PCM, is sodium acetate trihydrate $\left(\mathrm{C}_{2} \mathrm{H}_{3} \mathrm{NaO}_{2} .3 \mathrm{H}_{2} \mathrm{O}\right)$ with melting temperature of $58^{\circ} \mathrm{C}$ and latent heat capacity $265 \mathrm{~kJ} . \mathrm{kg}^{-1}$. Volume of used PCM that fills pores of metal foam was $184.3 \mathrm{~cm}^{3}$, respectively with using volumetric mass density $1.45 \mathrm{~g} . \mathrm{cm}^{-3}$, total mass of used PCM was $267.235 \mathrm{~g}$. In order to improve operational and technical characteristics of presented prototype was used sodium acetate trihydrate in the composition of $59.86 \%$ sodium acetate 
anhydrous and $40.14 \%$ water. Heat-storage unit consists of a copper pipe to which was soldered copper metal foam annulus. This object was enclosed with acrylic panels, respectively acrylic tube with air layer left above the metal foam, which compensates volume changes of PCM caused by phase changing and temperature increase. Manufactured prototype of heat-storage unit is shown in Fig. 5.

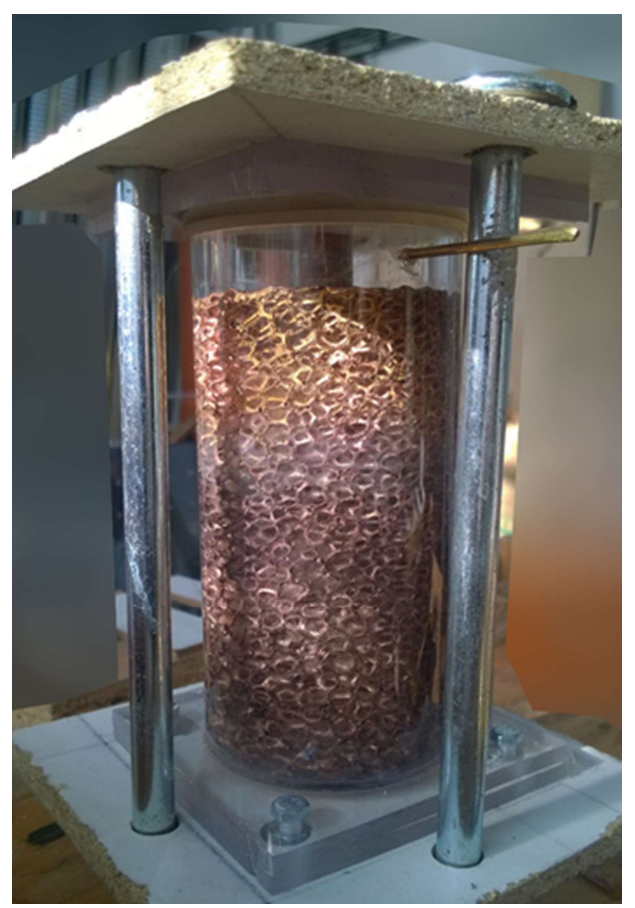

Fig. 5. Prototype of heat-storage unit based on PCM.

Table 1. Key parameters of experimental heat-storage unit

\begin{tabular}{|c|c|c|}
\hline Parameter & Values & Unit \\
\hline Shape of heat-accumulation unit & Annulus cylinder & $/$ \\
\hline Dimensions of heat-accumulation unit & $\Phi 50(12) \times 103$ & $\mathrm{~mm}$ \\
\hline Type of PCM & Sodium acetate trihydrate & $/$ \\
\hline Composition of PCM & $\begin{array}{l}59.86 \% \quad \text { sodium acetate } \\
\text { anhydrous, } 40.14 \% \text { water }\end{array}$ & $/$ \\
\hline Volume of PCM filling & 184.3 & $\mathrm{~cm}^{3}$ \\
\hline Latent heat of PCM & 265 & $\mathrm{~kJ}^{3} \mathrm{~kg}^{-1}$ \\
\hline Temperature of phase change & 58 & ${ }^{\circ} \mathrm{C}$ \\
\hline
\end{tabular}

The total possible amount of accumulated energy of heat-storage unit is determined by calculation according to Eq. 1 to Eq. 3:

$$
\begin{aligned}
& \mathrm{Q}_{\mathrm{A}}=\mathrm{Q}_{\text {solid }}+\mathrm{m} \cdot \mathrm{Q}_{\mathrm{L}}+\mathrm{Q}_{\text {liquid }} \\
& \mathrm{Q}_{\text {solid }}=\mathrm{m} \cdot \mathrm{c}_{\text {solid }} \cdot \Delta t_{\text {solid }}
\end{aligned}
$$




$$
\mathrm{Q}_{\text {liquid }}=\mathrm{m} \cdot \mathrm{c}_{\text {liquid }} \cdot \Delta t_{\text {liquid }}
$$

where, $Q_{A}$ - total amount of accumulated energy, $Q_{\text {solid }}$ - sensible heat of solid phase, $Q_{L}$ - latent heat of PCM, $Q_{\text {liquid }}$ - sensible heat of liquid phase, $m$ - weight of PCM. In Eq. 1 and Eq. 2 is $c_{\text {solid }}$, respectively $c_{\text {liquid }}$ specific heat capacity of solid, respectively liquid phase and $\Delta t_{\text {solid, }}$, respectively $\Delta t_{\text {liquid }}$ is difference between temperatures of solid, respectively liquid phase given the temperature of phase change of sodium acetate trihydrate.

The principle of physical experiment was based on flow of heat transfer medium (water) with temperature of $80^{\circ} \mathrm{C}$ through inner copper pipe of heat-storage unit what simulates source of useful heat from combustion engine. Heat flux from heat transfer medium flows through structure of metal foam where was heat transferred to sodium acetate trihydrate what change its temperature and phase with simultaneous accumulation of sensible and latent heat. The task of thus conceived experiment was to test the capability of heat transfer from the heat source through structure of metal foam to the PCM - sodium acetate trihydrate.

The presented experiment was performed at the Centre of Renewable Energy Sources of the Faculty BERG on experimental apparatus designed and manufactured by authors in which was installed heat-storage unit described in the previous section. Design of experimental apparatus was based on analysis of the input conditions in order to induce and control non-stationary processes from view of changing temperatures and phase changing of PCM. The experimental apparatus allowed supplied a constant heat flux from heat transfer medium which circulated in hydraulic circuit that is depicted in Fig. 6, where 1 heat-storage unit, 2 - flowmeter, 3 - flow control, 4 - flow heater, 5 - expansion vessel, 6 hydraulic pump, TC1 to TC4 - thermocouples probes.
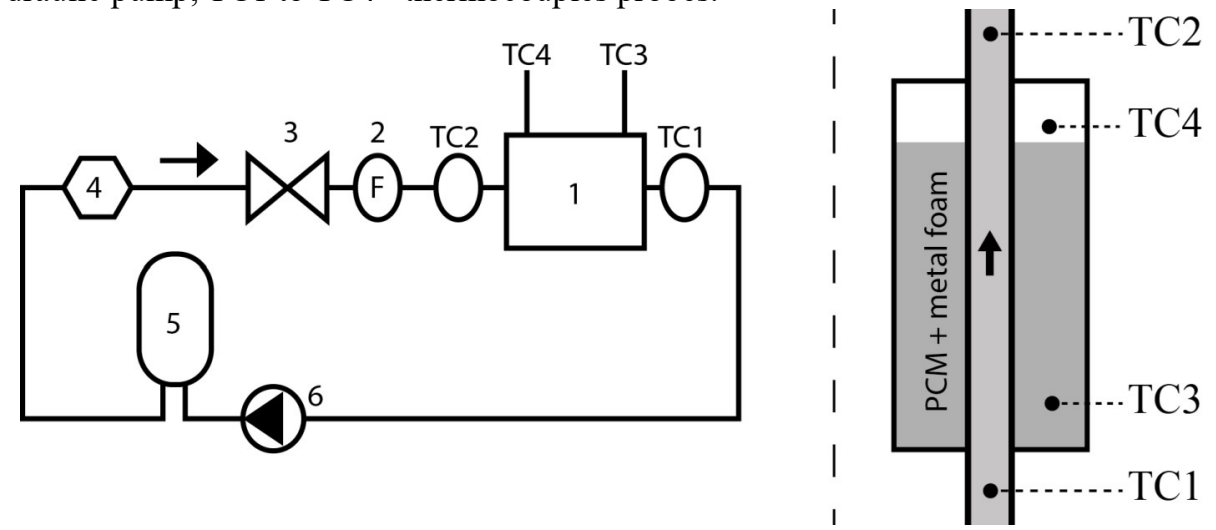

Fig. 6. Schematic diagram of hydraulic circuit (left) and heat-storage unit with depicted position of thermocouple probes (right).

In terms of verifying the functionality of the combination of the metal foam structure and sodium acetate trihydrate as a thermal-storage unit was necessary to measure the temperature of the PCM, i.e sodium acetate trihydrate as well as the temperature of the metal foam using thermocouple probes that are labeled as TC3 and TC4. Thermocouple probes labeled as TC1 and TC2 measured temperature of heat transfer medium before and after heat-storage unit, as it is depicted in Fig. 6. Experimental apparatus was supplemented with measuring devices, which consist from thermocouple probes KIMO TTKE-363 (type $\mathrm{K}$, range from $-40^{\circ} \mathrm{C}$ to $+400^{\circ} \mathrm{C}$ ), data acquisition system $\mathrm{KIMO}$ AMI 300 with temperature range from $-100^{\circ} \mathrm{C}$ to $+250^{\circ} \mathrm{C}$ with total uncertainty $\pm 0.4 \%$. Step of data recording was 10 $\mathrm{s}$. Flow rate of heat transfer medium was monitored with analogous rotameter with range 0.3 to $1.51 / \mathrm{min}$ and uncertainty $\pm 10 \%$ F.S. 
Status of phase changing of sodium acetate trihydrate was also monitored and recorded in the form of time-lapse video with using of camera located in the immediate vicinity of the heat-storage unit. The frequency of image capture was determined with respect to the rate of phase change to interval of 5 minutes. Camera lens was equipped with polarization filter, which eliminates the glare from outer acrylic tube of heat-storage unit. On the body of heat-storage unit was placed measuring tape allowing accurate tracking of phase change of sodium acetate trihydrate.

\section{Results and Discussion}

The presented analysis of proposed heat-storage unit is focused on part of verification of its functionality, which is in this case characterized by the first phase of working cycle, where heat-storage unit receives and accumulates heat energy from selected source. This process involves phase change of PCM, which has at the beginning solids phase and with raising temperature is changing to liquid phase. Melting point of sodium acetate trihydrate, which was used in presented work, is $58^{\circ} \mathrm{C}$.

In first phase of working cycle are sensible and latent heat accumulated. Their amount was for proposed heat-storage unit calculated using Eq. 1 to Eq. 3. Results of the calculation that reflects the real dimensions and characteristics of sodium acetate trihydrate is for amount of accumulated sensible heat $Q_{\text {solid }}$ equal 28,64 kJ. This heat is delivered within temperature difference $\Delta t=58-20^{\circ} \mathrm{C}$, since the ambient temperature at the start of experiment was $20^{\circ} \mathrm{C}$ and sensible heat is accumulated to the temperature of $58{ }^{\circ} \mathrm{C}$. Amount of accumulated latent heat $m . Q_{L}$ is with used weight of sodium acetate trihydrate equal to $70.8 \mathrm{~kJ}$. Because in the heat-storage unit was used sodium acetate trihydrate in the composition of $59.86 \%$ sodium acetate anhydrous and $40.14 \%$ water, it was necessary according to [19] rise temperature of $\mathrm{PCM}$ to $65^{\circ} \mathrm{C}$ to ensure phase change from solid to liquid in whole volume of heat-storage unit. Amount of sensible heat accumulated in this process that occurs in temperature difference $\Delta t=65-58^{\circ} \mathrm{C}$ is $\mathrm{Q}_{\text {liquidus }}=5.7 \mathrm{~kJ}$. The resulting delivered heat thus represents a value of $105.1 \mathrm{~kJ}$ from which useful heat that is stored for later use is $70.8 \mathrm{~kJ}$ (described for a proposed heat-storage unit).

Fig. 7 shows the temperature curve of the heat transfer medium simulating the useful heat of the combustion engine (TC1) and the temperature of PCM - sodium acetate trihydrate (TC3). Due to the used construction of heat-storage unit in terms of heat transfer from the inner copper tube, through the structure of the metal foam to the PCM, the temperature of the heat transfer fluid was selected to $80^{\circ} \mathrm{C}$. The temperature was experimentally determined at trial operation of experimental apparatus and provides sufficient heat flux and therefore temperature increase of the PCM. Visible anomaly of thermocouple probes TC1 in initial part of the curve represents the error in controlling of flow heater, but as can be seen, was quickly fixed. 


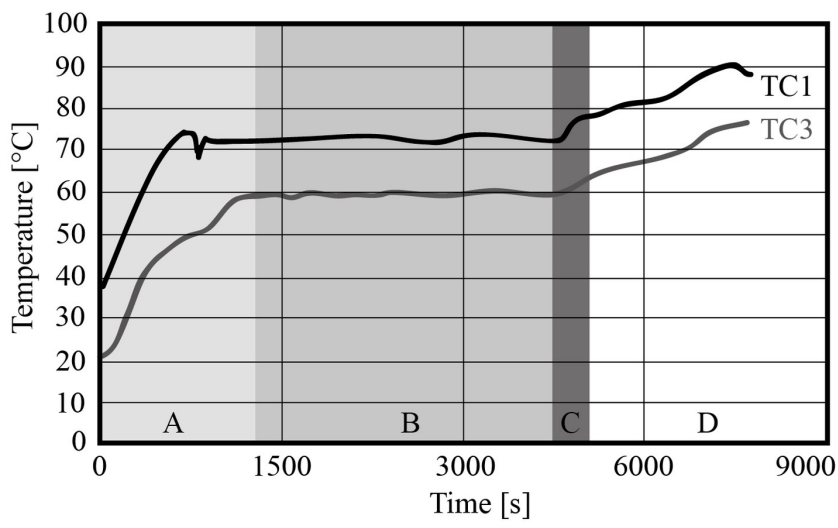

Fig. 7. Temperature curves of PCM and heat transfer medium at inlet to heat-storage unit.

From the shape of temperature curve for TC3 thermocouple probe, which measured temperature of sodium acetate trihydrate can be clearly recognize phases of accumulation. First part when sensible heat is delivered (labeled as A) is characterized with steep rise of temperature to the point at $58^{\circ} \mathrm{C}$. The second part is the accumulation of latent heat (labeled as B), which takes place at a standard temperature of $58^{\circ} \mathrm{C}$, horizontal course without major fluctuations proves the success of the concept in terms of its function which is storing latent heat of used PCM. After this part, which in the shown experiment ended at time $t=+4500 \mathrm{~s}$, the temperature of the heat-storage unit increased to $65^{\circ} \mathrm{C}$ ensuring complete phase change from solid to liquid state (labeled as C). The last part shown in Fig. 7 represents the experimental introduction of the extreme operating conditions in order to detect design and construction errors of the heat-storage prototype based on PCM.

Time step no. 1

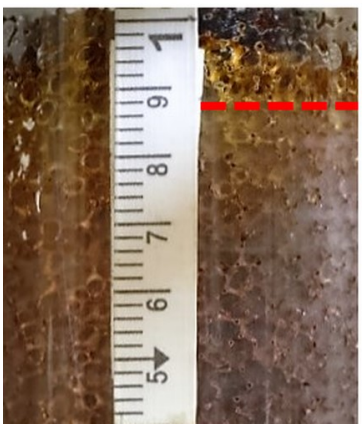

Time step no. 2

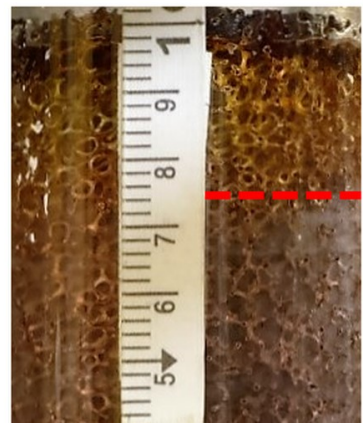

Time step no. 3

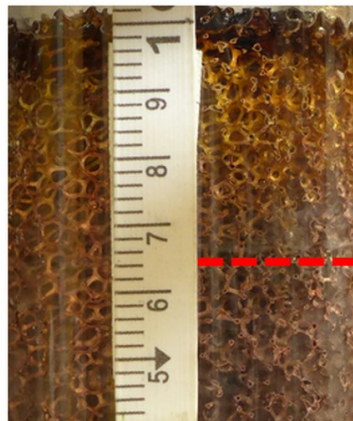

Fig. 8. Time-lapse image of phase change in heat-storage unit (red lines points to level between solid and liquid phase)

In addition to recording of the temperature from thermocouple probes TC1, TC2, TC3 and TC4, the process of heat accumulation of the proposed heat-storage unit was monitored by capturing the image at regular intervals without changing the unit position to the axis of the lens. In this way obtained time-lapse recording is possible to observe gradual phase change of PCM in the direction of the vertical axis of the heat-storage unit. Process of phase change started at the point with highest temperature, in this case at the point of entry of heat transfer medium into the inner copper pipe. Fig. 8 shows the phase change process in second part of accumulation, when sensible heat is already accumulated and the heatstorage unit begins to accumulate latent heat and thus changing its phase from solid to liquid. The rate of phase change of sodium acetate trihydrate was in vertical axis $3 \mathrm{~cm} . \mathrm{h}^{-1}$. 
However, it is necessary emphasized that the inner configuration of described heat-storage unit was not designed for quick heat accumulation (i.e. fast phase change of PCM), but for testing the functionality of the connection of PCM and metal foam structure.

Next steps in the development process leading to the final product are directed to the experiments related to the supercooling phase of working cycle. In term of design, it is necessary to ensure inner configuration of heat-storage unit in way that there will not occur uncontrolled nucleation of PCM and thus release the accumulated heat. The final step of the proposal, which is dependent on the successful supercooling and stabilization of PCM, is ensuring fully controllable nucleation (when heat is released) in appropriate way and at any time period.

\section{Conclusions}

Accumulation of useful heat of mining machines or combustion engines and its re-use is a relatively new concept that allows eliminating some of the negative operating conditions related primarily to unfavorable climatic conditions (cold engine start, temperature variations of operation mediums, elimination of thermal shocks, etc.). The presented concept of heat accumulation with use of heat-storage units based on PCM allows this energy store and uses it with time delays when it is needed. The uniqueness of the proposed concept lies in the simultaneous use of metal foam structure and PCM - sodium acetate trihydrate, which ensures sufficient thermal conductivity, which has low value when the sodium acetate trihydrate is use alone, and was limiting factor for further expansion of PCM storage. The functionality of this concept was verified by physical experiment that simulates the accumulation phase of heat-storage unit with use a heat source in the form of flowing heat transfer medium giving an analogy to conventional mining machines or combustion engines. Experiment was carried out in the Centre of Renewable Energy Sources Faculty BERG on experimental apparatus designed and manufactured by authors. Published results have shown the functionality of the concept in the first phase of accumulation of useful heat, where authors were able to successfully accumulate latent heat to PCM, which demonstrates temperature curve of PCM with flat part of curve at level of $58^{\circ} \mathrm{C}$, which is related to the phase change of PCM, and therefore, accumulation of heat.

\section{References}

1. H. Pavolová, T. Bakalár, D. Kudelas, P. Puškárová, Journal of cleaner production, 209, 1119-1125 (2019)

2. S. Elevli, B. Elevli, Acta Montanistica Slovaca, 15, 95-101 (2010)

3. M. Mohammadi, P. Rai, S. Gupta, Acta Montanistica Slovaca, 21, 1-8 (2016)

4. P. Křivík, P. Bača, M. Calábek, K. Micka, P. Král, Journal of Power Sources, 154, 518-522 (2006) doi: 10.1016/j.jpowsour.2005.10.029

5. J. Zimáková, S. Vaculík, P. Bača, D. Fryda, Acta Montanistica Slovaca, 20:3, 165-171 (2015)

6. Z. Dostál, M. Ďulík, Acta Montanistica Slovaca, 17:4, 310-314 (2012)

7. R. Rybár, D. Kudelas, M. Beer, Acta Montanistica Slovaca, 20:3, 172-180 (2015)

8. T.Y. Kim, A.A. Negash, G. Cho, Energy Conversion and Management, 124, 280-286 (2016) http://dx.doi.org/10.1016/j.enconman.2016.07.013

9. J. Shon, H. Kim, K. Lee, Applied Energy, 113, 680-689 (2014) http://dx.doi.org/10.1016/j.apenergy.2013.07.049 
10. F.R. Spellman, Water \& Wastewater Infrastructure: Energy Efficiency and Sustainability (CRC Press, Boca Rator, 2013)

11. G. Bajnóczy, Gagyi E. Pálffy, E. Prépostffy, A. Zold, Periodica Polytecinica SerChemEng, 43, 137 - 147 (1999)

12. H. Mehling, L.F. Cabeza, Heat and cold storage with PCM: An up to date introduction in to basics and applications (Springer, Berlin, 2008)

13. L. Huang, E. Günther, CH. Doetsch, H. Mehling, Thermochimica Acta, 509, 93-99 (2010) http://dx.doi.org/10.1016/j.tca.2010.06.006

14. R. Srikanth, C. Balaji, International Journal of Thermal Sciences, 111, 188-203 (2017) http://dx.doi.org/10.1016/j.ijthermalsci.2016.08.018

15. P. Himanshu, Thermal Energy Storage in Copper Foams filled with Paraffin Wax (Mechanical\& Industrial Engineering University of Toronto, Toronto, 2011)

16. D.H. Choi, J. Lee, H. Hong, Y.T. Kang, International Journal of Refrigeration, 42, 112-120 (2014) http://dx.doi.org/10.1016/j.ijrefrig.2014.02.004

17. A. Ansone, M. Dzikevics, A. Zandeckis, Energy Procedia, 95, 153-158 (2016) http://dx.doi.org/10.1016/j.egypro.2016.09.037

18. V. Kumaresan, P. Chandrasekaran, N. Maitreyee, A.K. Maini, R. Velraj, International Journal of Refrigeration, 36, 1641-1647 (2013)

19. E. Nohejl, Sezónní akumulátor tepla s minimálními ztrátami. URL: http://oze.tzbinfo.cz/akumulace-tepla/11626-sezonni-akumulator-tepla-s-minimalnimi-ztratami 